\title{
IMMUNOHISTOCHEMICAL DETECTION OF TETRASPANINS CD81 AND CD9 DISTRIBUTION IN BULL TESTIS AND EPIDIDYMIS
}

\section{Denisa Lipcseyová ${ }^{1}$, Jana Antalíková ${ }^{2}$, Jana Jankovičová ${ }^{3}$, Petra Cupperová ${ }^{4}$, Lubica Horovská $^{5}$, Katarína Michalková ${ }^{6}$, Michal Simon ${ }^{7}$}

\begin{abstract}
Mammalian spermatozoa, produced by the testes, must undergo maturation in the epididymis to gain the ability to fertilize an ovum. This process includes structural modifications, such as changes in the lipid and protein composition of the plasma membrane. The CD81 and CD9 proteins, which are members of tetraspanin superfamily, have been found to be involved in the fertilization process. Our study examined the presence of CD81 in the bull testis and epididymis, and then compared CD81's distribution profile with that of the molecule CD9. We detected CD81 in the basement membrane along the whole epididymis. In comparison, an abundant expression of CD9 molecule was found in the testis as well as in all three segments of the epididymis. Both molecules are part of the tetraspanin web, and are considered key elements in the sperm-egg interaction.
\end{abstract}

UDC Classification: 577, DOI: http://dx.doi.org/10.12955/cbup.v4.854

Keywords: CD molecules, immunohistochemistry, tissue.

\section{Introduction}

Fertilization is a highly regulated process that encompasses some essential steps in the fusion of an ovum with a sperm leading to formation of a zygote. Gamete cells arising from gonads pass through the genital tract of both male and female to undergo maturation. These lose, or gain, specific structural components to acquire fertilization capabilities. Although the fertilization process has been described in general, the exact roles of molecules involved in either gamete maturation or the intrinsic steps of sperm-egg interaction have not been fully elucidated. Accordingly, every molecule localized within the genital tract, or on the gamete surface, might relate to the complex mechanism of gamete fusion. Some of the protein-potential candidates for fertility control involve a cluster of differentiation (CD) molecules, particularly CD9 and CD81 (Kaji et al., 2000; Le Naour et al., 2000; Miyado et al., 2000; Tanigawa et al., 2008).

Our study focused on the distribution of the molecule CD81 in the bull testis and epididymis. Testes, the male sex paired gland, function in both reproductive and endocrine system. Their main roles are in spermatogenesis and production of androgens. The testes are structured with lobules containing highly coiled seminiferous tubules, each with a central lumen. In the testis, these tubules debouch into the vasa efferentia. Bull spermatozoa leaving the testis are inactive non-functional gametes. They transit through a single convoluted tubule, called the epididymis, located between the vasa efferentia and the vas deferens. This organ has three main sections: the head (caput), the elongated tubulous body (corpus), and the tail (cauda) and is responsible for sperm transport, storage, and maturation. Maturation involves the interaction of male gametes with lipids and proteins, which are synthesized and secreted from the epithelium of epididymis, in a region-dependent manner. Hence, in this process spermatozoa undergo many biochemical alterations that are modulated by the epididymis intraluminal content. The luminal fluid composition varies along the epididymis because of the varying pattern of

\footnotetext{
1 Denisa Lipcseyová, Institute of Animal Biochemistry and Genetics, Slovak Academy of Sciences, Ivanka pri Dunaji, Slovak Republic, denisa.lipcseyova@savba.sk

2 Jana Antalíková, Institute of Animal Biochemistry and Genetics, Slovak Academy of Sciences, Ivanka pri Dunaji, Slovak Republic, jana.antalikova@savba.sk

3 Jana Jankovičová, Institute of Animal Biochemistry and Genetics, Slovak Academy of Sciences, Ivanka pri Dunaji, Slovak Republic, jana.jankovicova@savba.sk

${ }^{4}$ Petra Cupperová, Institute of Animal Biochemistry and Genetics, Slovak Academy of Sciences, Ivanka pri Dunaji, Slovak Republic, petra.cupperova@savba.sk

${ }^{5}$ L'ubica Horovská, Institute of Animal Biochemistry and Genetics, Slovak Academy of Sciences, Ivanka pri Dunaji, Slovak Republic, lubica.horovska@savba.sk

${ }^{6}$ Katarína Michalková, Institute of Animal Biochemistry and Genetics, Slovak Academy of Sciences, Ivanka pri Dunaji, Slovak Republic, katarina.michalkova@savba.sk

${ }^{7}$ Michal Simon, Institute of Animal Biochemistry and Genetics, Slovak Academy of Sciences, Ivanka pri Dunaji, Slovak Republic, michal.simon@savba.sk
} 
gene expression and subsequent protein synthesis among the segments. The major modifications during sperm maturation include changes in phospholipid content of the plasma membrane, increase in surface negative charge and of disulfide bonds, the addition, elimination, or modification of surface proteins, and relocalization of surface antigens (reviewed in Sullivan et al., 2007).

The presence of CD9 within the whole bull genital tract has been previously established (Cupperová et al., 2014). We aim to investigate whether the molecule CD81 is present in the bull testis and epididymis, and to compare CD81's distribution profile with that of CD9. For immunohistochemical studies, an immunofluorescence assay was performed using polyclonal anti-CD81 and monoclonal anti-CD9 antibodies.

\section{Materials and Methods}

Antibodies

Polyclonal rabbit anti-CD81 (H121) antibody was obtained from Santa Cruz Biotechnology, Inc., CA, USA. Monoclonal antibody (mAb) IVA-50 (anti-CD9) was prepared according to standard hybridoma production protocol by Dusinsky et al. (1988) after immunization of BALB/c mice with bovine platelets. The specificity of mAb IVA-50 was verified in the III International Workshop on Leukocyte Antigens of Ruminants in Davis (USA) (Naessens et al., 1997).

Tissues

The bull testes and epididymides were obtained from a local slaughterhouse. Epididymides were dissected into the three segments: head, body, and tail. Tissue samples were sliced into small sections; fixed on cork blocks; and stored frozen at $-80^{\circ} \mathrm{C}$.

Indirect immunofluorescence

For immunohistochemical staining, we cut $5-\mu \mathrm{m}$-sections of frozen tissue using a Leica Cryocut 1800 cryostat (Leica Microsystems, Wetzlar, Germany). Tissue sections were fixed in a cold 1:1 ethanolacetone mixture for $5 \mathrm{~min}$, air-dried, washed in phosphate buffer saline (PBS), and treated with antiCD81 $\mathrm{H} 121$ antibody (1:100) or with IVA-50 mAb (hybridoma supernatant) for $1 \mathrm{~h}$ at $37^{\circ} \mathrm{C}$ in a humidified chamber. After washing in PBS, the tissue was incubated with goat anti-rabbit IgG-FITCconjugate (1:300 in PBS; Vector laboratories, Burlingame, CA, USA) or with horse anti-mouse IgGFITC-conjugate (1:300 in PBS) for 30 min in the dark at room temperature. Nuclear DNA of all tissue cells was stained by Vectashield-DAPI (Vector laboratories, Burlingame, CA, USA). Samples were evaluated under a Leica DM5500 B epifluorescence microscope. To record the immunofluorescence images a Leica DFC340 FX digital camera has been used and for their processing served Leica Advanced Fluorescence software.

\section{Results and Discussion}

The expression of CD81 and CD9 proteins in bull reproductive organs was detected, with antibody H121 or IVA-50 mAb, using immunofluorescent staining. There were significant differences between the reaction patterns of CD81 and CD9 in the tested parts and types of tissue (see Table 1).

In testis, there was no expression of CD81 throughout the entire tissue. In contrast, intensive staining confirmed an expression of CD9 in the basement membrane of seminiferous tubules (smooth muscle cells, collagenous tissue), while no expression of CD9 was found in the germinal epithelium, the developing forms of spermatozoa, and the tubular lumen. In epididymis, the distribution of both CD81 and CD9 varied along the whole organ, with the frequency of CD9 reaction much higher than CD81. Apart from the basement membrane, the signal of mAb IVA-50 was obvious in the epithelium and fluid of the lumen, including a clump of spermatozoa. In the head of the epididymis, the IVA-50 mAb staining was observed in the connective tissue (basement membrane), and a medium intensity of staining was detected in the lumen of the tubules. In the body of epididymis, the CD9 immunostaining extended to the secreta of the epididymal duct. A staining of high intensity was observed in the fluid filling the epididymal duct. The histochemical study showed no clear expression of CD9 in the clump of spermatozoa in the lumen, due to an "interfering reaction" of fluid that covered the spermatozoa. An intensive fluorescent reaction was observed along the epididymal duct, in various epithelial microvilli. A similar histochemical pattern was found in the tail of the epididymis. The occurrence of 
the CD81 molecule on the epididymal tissue was restricted to the basement membrane of tubules. In other parts of the epididymal tissue, only weak and insignificant reactions were recorded (Figure 1).

The differentiation antigens, CD81 and CD9, are considered potential co-players in the fertilization process. The CD81 molecule shares $45 \%$ of its amino-acid sequence homology throughout transmembrane domains with that of the $\mathrm{CD} 9$, and the antigens often interact to form a protein complex (Boucheix \& Rubinstein, 2001). Both molecules are members of the tetraspanin superfamily. Tetraspanins are abundant in cholesterol-rich microdomains (distinct from typical lipid rafts), where they associate with other regulation proteins such as integrins, kinases, or growth factor receptors, and thus, create the tetraspanin web involved in signaling processes (Boucheix \& Rubinstein, 2001; Lazo, 2007).

The antigens, CD9 and CD81, have been detected in mammalian and mouse egg plasma membrane and their cooperation in tetraspanin web has been suggested (Barraud-Lange \& Boucheix, 2013). The CD9 molecule has also been detected during spermatogenesis in spermatogonia, and in spermatocytes and round spermatids of mice and rats (Kanatsu-Shinohara, 2004; Ito et al., 2010). Furthermore, research has proven the presence of CD9 in the whole bull genital tract (Cupperová et al., 2014). The spermatozoa in epididymal lumen interact with small membranous vesicles, epididymosomes, which carry specific proteins. Sullivan et al. (2007) suggested that the proteins that are segregated to the vesicles are selectively transferred to the sperm plasma membrane. The epididymosomes are thought secreted in an apocrine manner by the epididymal epithelial cells. Moreover, Caballero et. al (2013) proposed CD9-positive microvesicles transfer to bovine spermatozoa during epididymal maturation. Based on the CD81 localization in the epididymis, we hypothesize that the CD81 molecule could be a part of the epididymosomes, as was suggested for CD9 and the bovine P25b protein (Frenette \& Sullivan, 2001).

Table 1: Expression of CD81 and CD9 in the bull testis and epididymis with the intensity of reaction: high, medium, low, or not detected.

\begin{tabular}{|c|c|c|c|}
\hline & & \multicolumn{2}{|c|}{ CD ANTIGEN } \\
\hline & & CD81 & CD9 \\
\hline & & \multicolumn{2}{|c|}{ Intensity of reaction } \\
\hline \multicolumn{4}{|l|}{ Testis } \\
\hline \multicolumn{2}{|c|}{$\begin{array}{l}\text { Cells of seminiferous tubules } \\
\text { lumen }\end{array}$} & not detected & not detected \\
\hline \multicolumn{2}{|c|}{ Germinal epithelium } & not detected & not detected \\
\hline \multicolumn{2}{|c|}{ Basement membrane of tubules } & not detected & high \\
\hline \multicolumn{2}{|l|}{ Epididymis } & & \\
\hline \multirow{3}{*}{$\begin{array}{l}\text { Luminal fluid and } \\
\text { cells (spermatozoa) }\end{array}$} & Head & not detected & medium (fluid) \\
\hline & Body & not detected & high (fluid) \\
\hline & Tail & low & high (fluid, sperm) \\
\hline \multirow{3}{*}{$\begin{array}{l}\text { Epithelium with } \\
\text { stereocilia }\end{array}$} & Head & not detected & not detected \\
\hline & Body & not detected & $\begin{array}{l}\text { medium (epithelium) / high } \\
\text { (stereocilia) }\end{array}$ \\
\hline & Tail & not detected & $\begin{array}{l}\text { medium (epithelium) / high } \\
\text { (stereocilia) }\end{array}$ \\
\hline \multirow{3}{*}{ Basement membrane } & Head & medium & high \\
\hline & Body & high & high \\
\hline & Tail & medium & high \\
\hline
\end{tabular}


Figure 1: Expression of CD81 and CD9 in testis and epididymis. Immunofluorescent staining of tissue using H121 (anti-CD81) or IVA-50 (anti-CD9) followed by IgG-FITC conjugates (green), nuclear DNA of cells staining by DAPI (blue).

\section{CD81}
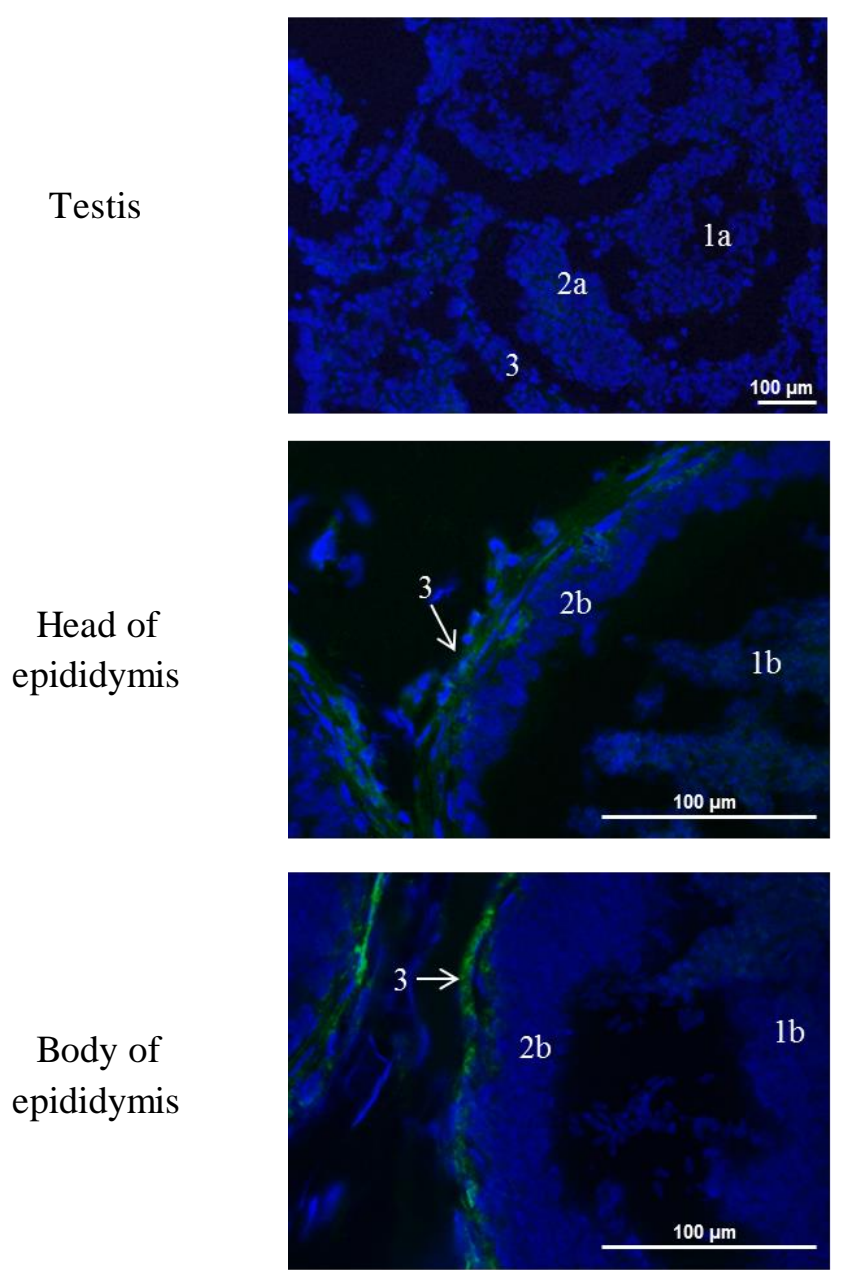

epididymis

Testis

Tail of epididymis

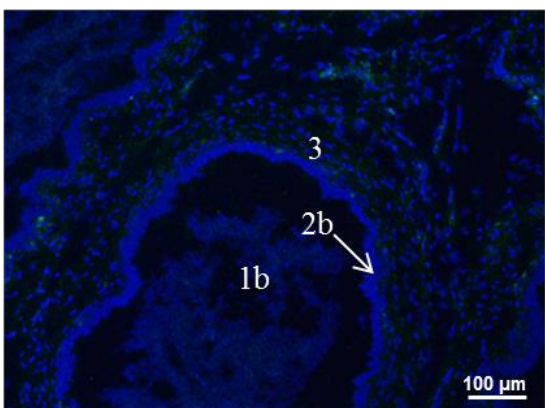

\section{CD9}

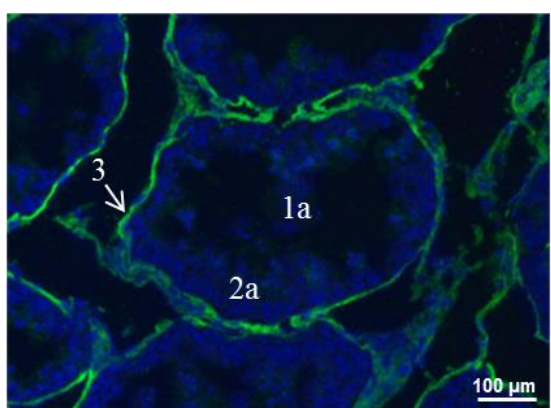

$1 \mathrm{~b}$
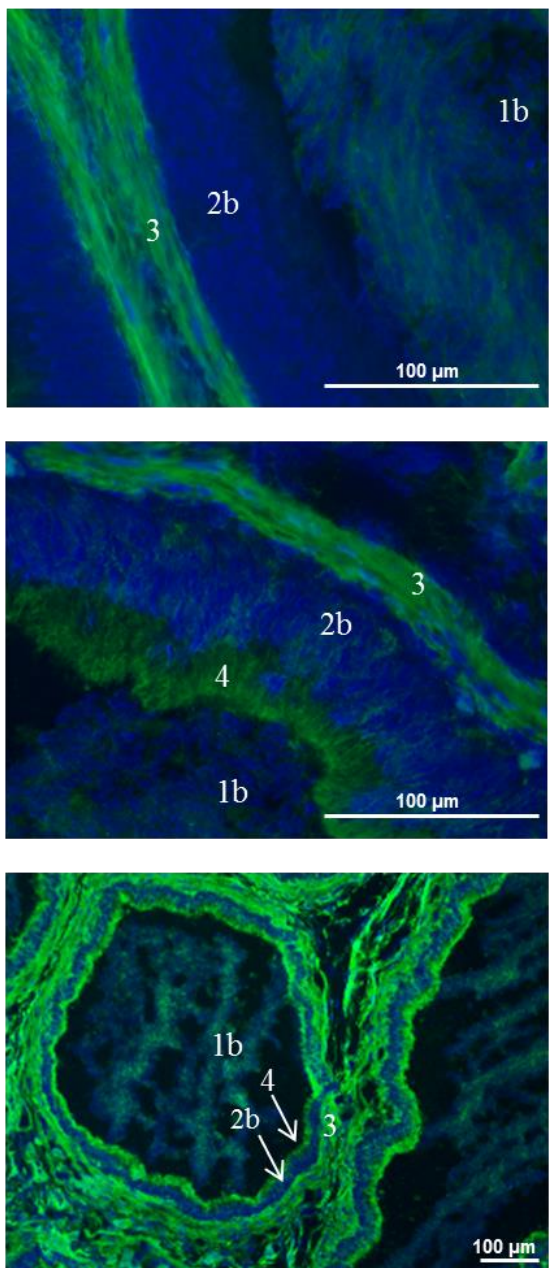

Testis: $1 \mathrm{a}$ - cells of seminiferous tubules lumen, $2 \mathrm{a}$ - germinal epithelium, 3 - basement membrane (smooth muscle cells); Epididymis: $1 \mathrm{~b}$ - luminal fluid and sperm, $2 \mathrm{~b}$ - epithelium with stereocilia, 3 - basement membrane (smooth muscle cells), 4 - stereocilia

Source: Authors 


\section{Conclusion}

In spite of the high homology of the molecules CD81 and CD9, our results showed they have different immunohistochemical reaction patterns in the bull testis and epididymis. The presence of tetraspanin CD81 was restricted to the bull epididymis, whereas CD9 was detected in both the epididymis and testis.

\section{Acknowledgement}

This study was supported by grants VEGA 2/0037/16 and APVV-0137-10, and the bilateral project SAV-AV ČR 15-05. We would like to thank Zuzana Nádaždyová for her excellent technical assistance.

\section{References}

Barraud-Lange, V. \& Boucheix, C. (2013). The Role of Tetraspanin Complexes in Egg-Sperm Fusion. In F. Berditchevski, \& E. Rubinstein (Eds.), Tetraspanins (pp. 203-231). Dordrecht, The Netherlands: Springer Science+Business Media.

Boucheix, C., \& Rubinstein, E. (2001). Tetraspanins. Cellular and Molecular Life Sciences, 58(9), 1189-1205.

Caballero, J. N., Frenette, G., Belleannée, C., \& Sullivan, R. (2013). CD9-Positive Microvesicles Mediate the Transfer of Molecules to Bovine Spermatozoa during Epididymal Maturation. PLoS ONE, 8(6), e65364.

Cupperová, P., Simon, M., Antalíková, J., Michalková, K., Horovská, L., \& Hluchý, S. (2014). Distribution of tetraspanin family protein CD9 in bull reproductive system. Czech Journal of Animal Science, 59(3), 134-139.

Dusinsky, R., Simon, M., \& Nouzovská, D. (1988). Production of monoclonal antibodies against cell surface antigens in cattle. Veterinarni Medicina, 33(3), 135-141.

Frenette, G., \& Sullivan, R. (2001). Prostasome-like particles are involved in the transfer of P25b from the bovine epididymal fluid to the sperm surface. Molecular Reproduction and Development, 59(1), 115-121.

Ito, C., Yamatoya, K., Yoshida, K., Maekawa, M., Miyado, K., \& Toshimori, K. (2010). Tetraspanin family protein CD9 in the mouse sperm: unique localization, appearance, behavior and fate during fertilization. Cell Tissue Research, 340(3), 583594.

Kaji, K., Oda, S., Shikano, T., Ohnuki, T., Uematsu, Y., Sakagami, J., \& Kudo, A. (2000). The gamete fusion process is defective in eggs of Cd9-deficient mice. Nature Genetics, 24(3), 279-282.

Kanatsu-Shinohara, M. (2004). CD9 Is a Surface Marker on Mouse and Rat Male Germline Stem Cells. Biology of Reproduction, 70(1), 70-75.

Lazo, P. A. (2007). Functional implications of tetraspanin proteins in cancer biology. Cancer Science, 98(11), 1666-1677. Le Naour, F., Rubinstein, E., Jasmin, C., Prenant, M., \& Boucheix, C. (2000). Severely reduced female fertility in CD9deficient mice. Science, 287(5451), 319-321.

Miyado, K., Yamada, G., Yamada, S., Hasuwa, H., Nakamura, Y., Ryu, F., \& Mekada, E. (2000). Requirement of CD9 on the Egg Plasma Membrane for Fertilization. Science, 287(5451), 321-324.

Naessens, J., Howard, C. J., \& Hopkins, J. (1997). Nomenclature and characterization of leukocyte differentiation antigens in ruminants. Immunology Today, 18(8), 365-368.

Sullivan, R., Frenette, G., \& Girouard, J. (2007). Epididymosomes are involved in the acquisition of new sperm proteins during epididymal transit. Asian Journal of Andrology, 9(4), 483-491.

Tanigawa, M., Miyamoto, K., Kobayashi, S., Sato, M., Akutsu, H., Okabe, M., \& Miyado, K. (2008). Possible involvement of CD81 in acrosome reaction of sperm in mice. Molecular Reproduction and Development, 75(1), 150-155. 